DOI: $10.2478 /$ ausfm-2020-0006

\title{
Sights and Sounds of Big Data: Ryoji Ikeda's Immersive Installations
}

\author{
Mihály Lakatos \\ Sapientia Hungarian University of Transylvania (Cluj-Napoca, Romania) \\ E-mail: lakatosmiska@kv.sapientia.ro
}

\begin{abstract}
The Japanese multimedia artist Ryoji Ikeda's work can be interpreted as a contact between mediums, but also as a contact between disciplines. Most of his video installations are based on concepts borrowed from the field of mathematics, physics or information technology. In this paper I will examine Ikeda's audiovisual installations by presenting these multimedial installations as possible methods of visualizing digital data in the context of contemporary art. Considering their digital and abstract nature, these works can also be analysed as unique audiovisual environments built from different media based on the same data-sets, offering the possibility of immersion. By unfolding the medial relations within Ikeda's work I will try to demonstrate how the combination of sight and sound creates the intersensual experience of getting in touch with digital data. ${ }^{1}$
\end{abstract}

Keywords: Ryoji Ikeda, data visualization, video installation, electronic music.

Despite the current economic, technologic and political fetishization of big data $^{2}$ and its utility, it is a fact that data is never in and of itself pure: it is always interpreted and modified for presentation. Big data being a relatively new concept, the art as well as the new kind of aesthetics based on this is also a fresh movement within the global art world. Artists from all around the world have been transforming

1 This work was supported by a grant of the Ministry of National Education, CNCS - UEFISCDI Romania, project number PN-III-P4-ID-PCE-2016-0418.

2 The definition of big data on Wikipedia: "Big data is a field that treats ways to analyze, systematically extract information from, or otherwise deal with data sets that are too large or complex to be dealt with by traditional data-processing application software." https:// en.wikipedia.org/wiki/Big_data. Last accessed 20. 08. 2019.

Big data is a huge opportunity both economically and politically. Leading technology companies like Facebook, Alphabet Inc. or Amazon mainly built their economic success on analysing and selling data extracted from their users. Modern authoritarian governments use big data technology in order to analyse and monitor the citizen's online behaviour as a form of digital surveillance. 
streams of data into abstract aesthetic forms. Their works sometimes function as a commentary on the world we live in, an artistic examination of contemporary phenomena, other times data is transformed into such forms that it becomes an experience unto itself. (For example, Aaron Koblin took 24 hours of flight data and turned it into a 60-second video showing the flow of air traffic across the United States in his work titled Flight Patterns [2011]; Nathalie Miebach turned weather data into elaborate and abstract sculptures made of wicker and coloured beads, having it accompanied by musical scores written for a string quartet, based on the same data pattern as the sculpture in Changing Weather [2006].)

The Japanese-born, Paris-based multimedia artist Ryoji Ikeda is a key figure in using big data as the base of his audiovisual art. He is a composer who makes music from noises (non-musical sounds) and glitches accompanied by abstract and minimalistic visual stimuli. Ikeda's performances, installations and artworks explore the building blocks that constitute the flow of data that increasingly permeates our world (sine waves, sound pulses, pixels of light, binary digits and numerical data). Using digital technologies, his audiovisual performances and concerts ${ }^{3}$ offer a unique perception of our multimedia environment and culture. These artworks, based on scientific concepts borrowed from the field of mathematics, physics or IT can be analysed as collaboration between disciplines, as discourse between science and art.

In this paper I will examine Ikeda's audiovisual installations, focusing on the juxtaposition of digital sounds and images, scrutinizing the musical means used by Ikeda and inspecting the nature of data-based images and their relation to analogue image. I will describe these unique audiovisual environments created by this juxtaposition as a standalone form of installation art. I propose that Ikeda's installation works are not just unique audiovisual environments engaging the human senses but each of these works examines the basic characteristics of installation art and the artistic possibilities granted by digital technology and big data. Furthermore, these works can also be seen as a form of post-human aesthetics, and works that test the threshold of human perception. And perhaps these works

3 E.g. test pattern (an ongoing audiovisual installation series, started in 2008), datamatics (an ongoing series, started in 2006, which consists of audiovisual concerts and installations), C4I (a series of audiovisual concerts, performed from 2004 until 2006), formula (a series of audiovisual live concerts, performed from 2000 until 2005), or superposition (an ongoing series of audiovisual performances, employing human performers and audiovisual installations, started in 2014). Ikeda performs and exhibits worldwide at spaces such as the Museum of Contemporary Art Tokyo, the Barbican Centre in London, the Pompidou Centre in Paris or the EYE Film Museum in Amsterdam. In 2001, Ikeda was awarded the Ars Electronica Golden Nica prize in the digital music category and he was short-listed for a World Technology Award in 2003. In 2014 he was awarded the Prix Ars Electronica Collide @ CERN residency, which granted him access to the CERN headquarters in Switzerland to work with data produced at the Large Hadron Collider. 
can also be analysed as tools to understand different aspects of the functioning mechanisms of our postdigital ${ }^{4}$ environments.

\section{The Sound}

Ikeda started his career as a DJ in the Tokyo club scene, being a music composer turned into multimedia artist. Most of his artworks are based on structures borrowed from music (for example rhythmical repetition of images), moreover the main concepts of his installations can be traced back to ideas firstly examined through the medium of electronic music. His albums $+/-(1996), 0^{\circ} \mathrm{C}$ (1998), matrix (2000), op (2002), dataplex (2005), test pattern (2008), supercodex (2013), The Solar System (2015), code name A to $Z$ (2017), and music for percussion (2018) pioneered a new world of electronic music which can be described as a strange, experimental mixture of minimal techno, modern classical music and Japan's experimental music. Ikeda's sound is built on a variety of "raw" sound states, such as sine wave tones, noises, often using frequencies at the edges of the range of human hearing. Rhythmically, Ikeda's music is very complex, with beat patterns made up of glitch and beep sounds which create the semblance of a drum machine. His work also resembles ambient music, some of the tracks on his albums are concerned with slowly evolving soundscapes, with little or no sense of rhythm.

According to Torben Sangild, Ikeda's music focuses on sounds "that are rarely recognized in everyday life; the forgotten secondary sounds of electronic equipment" $(2004,258)$. These sounds are withdrawn from their regular, concrete environment and inserted in an abstract, empty, sterile sound space where, endowed with a relative autonomy, they can be perceived as music. This process of decontextualization has the ability to influence the perception of digital microsounds in daily life, thus providing the opportunity "to relate more consciously to the sounds we are involuntary exposed to in our techno-environments, and to become aware of the stress they inflict upon us as well the as the potential beauty they possess" (Sangild 2004, 266).

4 Mel Alexenberg defines postdigital art as "artworks that address the humanization of digital technologies through interplay between digital, biological, cultural, and spiritual systems, between cyberspace and real space, between embodied media and mixed reality in social and physical communication, between high tech and high touch experiences, between visual, haptic, auditory, and kinesthetic media experiences, between virtual and augmented reality, between roots and globalization, between autoethnography and community narrative, and between web-enabled peer-produced wikiart and artworks created with alternative media through participation, interaction, and collaboration in which the role of the artist is redefined" $(2011,10)$. 
The digital glitch sounds in most cases indicate malfunction, some kind of error, a failure within a digital device and they occur abruptly, distorting the flow of sounds, becoming an alien piece in the soundscape. However, Ikeda (as many other electronic musicians $s^{5}$ ) uses these glitch sounds in a very precise way for constructing beat patterns, they are never accidental or random. And as Kim Cascone $(2002,18)$ notices, this technique of exposing the minutiae of errors and artifacts for their own sonic value forces the listener to examine the preconceptions of failure, malfunction and detritus more carefully. The listeners become aware of the technological apparatus used to create the music, but also of the apparatus used for playback, as Theodor W. Adorno notes: "there is only one point at which the gramophone interferes with both the work and the interpretation. This occurs when the mechanical spring wears out" (1994, 607). Thus, glitch sounds function as stylistic tools in contemporary electronic music, reflecting the digital nature of the music.

Ikeda uses the sine wave tone ${ }^{6}$ in the album entitled matrix, which is one of the highlights of his ambient works. Philip Brophy defines sine wave tone as "the sonic DNA in formulating electronic music" and out of that "counter to just about any other sound in the world, the sine wave tone is the sonic realization of a graphical visual display. It requires no imagined synthetic corollary because its sonority is the outcome of its visuality, and its visuality is the outcome of its mathematical determination. For example, the sounds of a flute, a seagull, or a baby laughing result from the pre-existence of their physical manifestation. Conversely, the sounding of a sine wave tone results from a mathematical computation; being a visualized theorem, its sound is not dependent on the physical, acoustical world" $(2015,226)$.

+/-plays on the threshold of human perception with tones the listener only becomes aware of upon their disappearance. The quality and the technical capabilities of the playback device is also important in this case: "with normal or poor speakers one almost doesn't hear anything until this last track on the album stops and a sudden release of tension is felt" (Sangild 2004, 265). Dataplex, an album released by RasterNoton $^{7}$ in 2005, came with a warning sticker attached, which said: "Caution! This CD contains specific waveform data that performs a data-read test for optical drives. The last track will cause some CD players to experience playback errors, with no

5 There is a whole subgenre of electronic music built around digital glitches, and created by groups like Oval, Pan Sonic, Autechre, etc.

6 A tone with a single frequency, also known as a pure tone or sinus tone. Its waveform (the pattern of sound pressure variation, usually displayed as a two-dimensional graph of amplitude against time) is that of a sine wave (mathematical curve that describes a smooth periodic oscillation).

$7 \quad$ A now defunct record label founded by Olaf Bender, Carsten Nicolai and Frank Bretschneider in 1996, which was meant to be a platform or a network covering the overlapping border areas of pop, art and science. It realized music projects, publications and installation works. 
damage to equipment." The album test pattern was accompanied with a similar warning message. "Caution! This CD contains specific waveform, impulse and burst data that perform a response test for loudspeakers and headphones. High volume listening of the last track may cause damage to equipment and eardrums." Testing the limits of human perception (moreover the biological limitations of the human body) and the capabilities of playback devices are the core concepts of these works, and these are the concepts further considered within the context of the audiovisual installation series test pattern as I will point it out hereinafter.

The musical piece written by Ikeda in 2016, called Body Music [for duo] also explores the relation between the human and the inhuman in an interesting manner: two musicians perform the complex rhythm patterns which Ikeda made with software, using only their bodies (clapping their hands, stamping their feet).

The ongoing project started in 2000, titled $A$, consists of sound installations built around the musical note A. The A note (also known as La) is generally used as a standard for tuning. When an orchestra tunes, the oboe plays an A and the rest of the instruments tune to match that pitch. This concert pitch, however, has varied over the past few hundreds of years, from Bach's era to the recent definition by the International Organization for Standardization, which defines this pitch at $440 \mathrm{~Hz}$. Therefore the A note as the standard pitch for orchestras has never been precisely defined, and still varies depending on orchestras or countries. The installments of the $A$ series consist of varying number of loudspeakers that play the different frequencies of the note A. Visitors ${ }^{8}$ experience their own particular interference/ oscillation in their ears which constantly and interactively changes and resonates at both physical and intrapersonal levels in accordance to their own movements as they figuratively walk through the history of music standardization.

Thus, Ikeda's music incorporates data-based sounds that can only be found within digital environments and uses these sounds in a self-reflexive manner, defining a strong bond between the listener, the technical apparatus, and the artwork itself. Ikeda's musical pieces are far more than deconstructed soundscapes, they also function as sonic experiments to test both the technical apparatus used in the playback process and the listener's auditory senses, establishing a sensorial relation between the listener and the machine, between the human and the inhuman. Moreover, based on the notions of the highly influential Fluxus artist and theorist Dick Higgins, who coined the term intermedia (a term primarily used to describe various inter-disciplinary art activities that occurred between genres in

8 Margaret Morse recommends the term "visitor" over spectator or viewer in the case of art installations $(1990,155)$, so in this paper I will use this term. 
the 1960s), and who in his essay Synesthesia and Intersenses: Intermedia identifies John Cage's musical experiments as pieces that explore the intermedia between music and philosophy $(1984,26)$, Ikeda's musical works can also be interpreted as pieces that explore the relations between music and technology, music and musicology, music and sound design, music and the human sensory reception. However, I would rather define these connections as inter-disciplinary relations than as intermediality, nonetheless, an intermedial approach could be useful for the interpretation of Ikeda's audiovisual works.

\section{The Visuals}

As in the case of sound, the images used by Ikeda are purely synthetic, data-driven images. Data-driven images can only be created or experienced with some kind of coding/decoding device, they are immaterial, they have no weight, they do not even exist without these devices. In a way they function just like the sine wave tones, but there is a main difference: digital images sometimes are representations of the real physical world, they reproduce a fragment from it. However, in his installations Ikeda uses abstract digital images, created within digital environment, without any connection to the physical world, although, in some cases these images contain signs with explicit semantic values (like numbers, geometric forms etc.), but these signs - just like the sounds in his music - are withdrawn from their context.

The visual language used by Ikeda shares some features with the visual language of the structuralist filmmakers of the 1960s and 1970s. The four main concepts (the elimination of the aestheticizing attitude of the early avant-garde film, the examination of the filmic apparatus with the film itself, minimalism and conceptualism) that define structuralist/materialist films also characterize Ikeda's visual language. We cannot speak of any kind of aestheticizing attitude. Some of his works are openly dedicated to examine the technical apparatus (for example the test pattern series, which - as the title implies - tests the performance of visualization devices). His works are minimalist (they use monochromatic abstract graph-like shapes and geometric forms) and conceptual (each work is built around a well-defined concept). The subject of self-reflexive examination in his works is not the celluloid film material or the analogue, mechanical movie projector, ${ }^{9}$ but

9 Like in the case of Tony Conrad's experimental film from 1966 titled The Flicker, which is now recognized as a key work of structural filmmaking and which consists only of black and white frames. The changing of these frames during projection causes a stroboscopic effect, highlighting the functioning mechanisms of the cinematic apparatus: rolling frames transforming the light into projected moving images. 
rather high-performance (high display resolution, high image refresh operation) digital video projectors and computer hardware with high computing performance to visualize big data sets through these video projectors.

The digital nature of these abstract images also implies the use of visual signs that can be interpreted as glitches, however like in the case of Ikeda's musical pieces, the use of glitch in his visual work is a stylistic tool not just to emphasize the mediality of these images,$^{10}$ but also to unfold digital imaging processes. Rosa Menkman describes visual glitch as a powerful interruption in the flow of images (for example, in a television broadcast), which occurs as a result of unexpected malfunction, and notes that the artistic use of glitches may unfold not just the medial characteristics of a digital image, but also the political and social connotations of these (2011, 7-11). The images used in the datamatics series, for example, contain a lot of visual signs that can be identified as glitches: half-rendered images, different coloured blank spots, draft-like graphics - glitches that indicate disruptions in the rendering process $^{11}$ of these images. However, Ikeda uses these glitches intentionally, as integral parts of the images, not just to unveil the functioning mechanisms of digital image rendering but also to capture an in-between state: no longer data, not yet image. [Figs. 1-4.]

Margaret Morse suggests that 'the 'video' in video installation stands for contemporary image-culture per se. [...] each installation is an experiment in the redesign of the apparatus that represents our culture to itself: a new disposition of machines that project the imagination onto the world and that store, recirculate, and display images; and, a fresh orientation of the body in space and a reformulation of visual and kinesthetic experience" $(1990,155)$. In Ikeda's case, the moving images are deeply rooted in our postdigital, data-based image making processes indicating that digital images used as the raw material of video installations emerge as the "natural" world upon which the artists exercise their influence as subjects (see Morse 1990, 161). Continuing this line of thought, in the postdigital era it is not only the images that can be seen as the raw material of the installations but, as we see in Ikeda's works, the digital data itself too.

10 According to Clement Greenberg (1961, 133-139) in the context of modern arts, abstraction becomes the indicator of mediality in a self-reflexive manner. Abstraction simplifies the paintings to their core characteristics: the canvas becomes the indicator of the two-dimensional nature of painting, the pigments of paint become the indicator of materiality, the colours, the lines and the forms become the indicators of basic forms of pictorial self-expression.

11 Rendering or image synthesis is the automatic process of generating image from data by means of computer programmes. 


\section{The Relation between the Sound, the Visuals and the Space}

As we have seen, the sounds and the images used by Ikeda share strong similarities: both are created within digital environments (incorporating data-based visual and sonic elements that can only be found within these environments, elements without any kind of representational value), both can be showcased with the use of digital devices, and both have self-reflective characteristics. To further examine the relation between sound and image, Cindy Keefer's notions about Visual Music can be a good starting point. Keefer, based on William Moritz defines Visual Music as "a music for the eye comparable to the effects of sound for the ear" $(1986,22)$. She considers Visual Music as a subgenre of experimental movies and lists artists like Oskar Fischinger, Len Lye, Norman McLaren and Jordan Belson as Visual Music filmmakers. Keefer (2015, 84-85) identifies four phenomena that can be considered Visual Music: 1) the translation of a specific musical composition (or sound) into a visual language, 2) creating a visual structure of a kind or style of music (a new composition created visually but as if it were an aural piece), 3) a direct translation of image to sound (e.g. images drawn or scratched onto a film's soundtrack, directly converted to sound when the film is projected, or sometimes shown simultaneously, like in Oskar Fischinger's Ornament Sound experiments from 1932), 4) a static visual composition created as the visual interpretation of a specific music (e.g. Keefer mentions the paintings of Paul Klee, but Jean-Michel Basquiat's painting titled Horn Players from 1983 could be a good example too). Considering the relation between sound and sight, Ikeda's audiovisual installations can be defined as Visual Music in the sense of the first, the third and the fourth categories described by Keefer.

Most of the images used by Ikeda can be analysed as a translation of musical composition into a visual language. In every audiovisual installation created by Ikeda the sounds and the images are strictly juxtaposed, accurately coordinated: a change in the soundscape always and immediately (without any delay) implies the changing of the sight.

One of his first multimedia projects, titled cyclo., created in 2000 together with Carsten Nicolai, ${ }^{12}$ is a great example for direct translation of images to sounds. In this project, Ikeda and Nicolai worked with software that enabled real-time

12 Carsten Nicolai (also known as Alva Noto or Noto) is a German music producer and multimedia artist, probably best known as the composer of the soundtrack for the 2015 Alejandro González Iñárritu movie The Revenant. 
graphical representation of sounds, allowing them to compose music based on various images. The graphic appearance of the images determined the recorded sounds. As a result of the project, a CD-ROM with a catalogue-like attachment was released, the attachment containing the two-dimensional graphical representation of sounds on the CD-ROM.

Two pieces from the test pattern series, the painting-like pieces exhibited in Taipei Fine Arts Museum between August 10-November 17, 2019 and the images from the book released by Onestar Press in 2017 can be seen as static visual interpretations of Ikeda's sound. The static, barcode-like, printed images are not just still image variations of the moving images used in the audiovisual installations, but also a kind of static visual interpretation of Ikeda's music (the pictures precisely represent the rhythmic structures used by Ikeda).

We can further scrutinize the relation between sound and sight in Visual Music through the notions of Yvonne Spielmann. Spielmann defines the difference between intermedia, mixed media and multimedia by suggesting that intermedia deals with the interrelationship between distinct media that merge with each other, the term multimedia should be applied in the case of synchronous occurrence of different art forms within the frame of one integral medium that at the same time remain distinct from each other (such as opera or theatre) and the term mixed media should be applied in the case when a medium incorporates elements of another (for example photography in film or painting in photography) (2001, 56-57). Based on Spielmann's notions, Visual Music is multimedia. The translation of a musical composition to a visual language does not blur the medial borders, the medium of image (still or dynamic) and the medium of sound remain easily distinguishable. For example, in Ikeda's case, despite the synchronous occurrence, the accurate juxtaposition and the similar stylistic elements, the sound and the image remain two separate medium with solid medial borders.

spectra (started in 2000, ongoing) has been the first project in Ikeda's body of work that introduced space as a major determinant of the spectacle. In this series, Ikeda created large-scale site-specific installations employing intense white light (accompanied by a sine wave tone) as a sculptural material. Ikeda describes the white light employed in this series as "one of the purest forms of transformation from electricity"13 (in this analogy, sine wave tones can also be interpreted as one of the purest forms of transforming electricity to sound). The installations are designed in response to public sites, altering the landscape. Through these installations visitors witness how the transformation of electricity to light alters the environment itself.

13 http://www.ryojiikeda.com/project/spectra/. Last accessed 18. 12. 2019. 
The sight, the sound and the space are combined to create the sensory experience. [Figs. 5-6.] The datamatics series ${ }^{14}$ (started in 2006, ongoing) could be interpreted as a further experimentation with space, especially with the museal space and the exhibiting traditions (institutionalized ways of exhibiting art) implied by this space.

Due to their large scale and the way they are installed, some installments from the series offer the possibility of immersion for the visitors. The data.tron [advanced version], for example, was set up in an abandoned armoury in New York City, between May 20 and June 11, 2011, and the projected image appeared on an 18-metre-high and an 18-metre-wide canvas set in the middle of the hall, creating a large-scale "wall of visualized data." In the installation titled data.path (set up in the Fundacion Telefónica, in Madrid, between September 28, 2013 and January 5, 2014) 7 projectors were used to project horizontally moving images onto two parallel walls of a corridor, creating the effect of stepping inside a "data cable." Continuous motion of images greatly alters the perception of space and makes the visitor feel as if they were flowing with data. The installment data.tron [8K enhanced version], set up in Ars Electronica Center in Linz, AT, between January 1, 2009 and December 31, 2010 can also be mentioned, in which 8 high capacity projectors combined with 9.2ch sound system filled the whole gallery hall with data, literally immersing the visitors in the work. Through their large scale and the possibility of immersion offered, these works reflect the huge amount of digital data that surround us in our daily lives: data become visualized both literally and figuratively.

In the installation data.scan, Ikeda uses a completely different approach. He exhibits moving images based on datasets containing the results of contemporary microbiological and astronomical researches displayed on LCD screens placed on the top of wooden boxes. By presenting these datasets as museal artifacts, Ikeda channels the data as an artistic material into a larger, art historical context. The spatial arrangement of the data.matrix [ $\left.n^{0} 1-10\right]$ also mimics a museal space. In this variation the data-based motion pictures are projected on the wall, imitating paintings hung on the wall. Visitors can walk through the exhibition and watch the moving images, enjoying the experience at their own pace.

The relationship between digital data and analogue representational modes is also explored in the installation titled data. film [ $\left.n^{\circ} 1-a\right]$. This work uses series of analogue $35 \mathrm{~mm}$ film rolls mounted in a light box. The image on the film is constructed from microscopically printed data codes and patterns from pure digital sources, while

14 datamatics is an art project that "explores the potential to perceive the invisible multi-substance of data that permeates our world. It is a series of experiments in various forms - audiovisual concerts, installations, publications and CD releases - that seek to materialise pure data" http:// www.ryojiikeda.com/project/datamatics/. Last accessed 18. 12. 2019. 
the unusual proportions of the light box ( $4 \mathrm{~cm}$ high, 10 metres wide, $4 \mathrm{~cm}$ deep) create a long, narrow strip of film. Only upon close examination by the viewer can the film and its contents be recognized. From afar it looks like a simple, shining white stripe mounted on the wall, but if the viewer leans closer the details emerge. This process can be seen as allusion to photo enlargement, moreover it exposes an analogue way of storing and exhibiting digital data through the technical apparatus of analogue photography.

The work entitled data.scape (set up on December 16, 2016) is an experiment to display data as an integral part of a building's architecture. Being a site-specific, permanent audiovisual installation, the datasets are visualized on a 100-metre-wide and 4-metre-high LED screen mounted on one of the outdoor walls of the Sydney International Convention Centre: moving images based on datasets integrated in the medium of architecture. In the datamatics series Ikeda does not just explore the modes of materializing data through different technologies and different media, but every piece also functions as a self-reflexive examination of the medium itself and of the technical and stylistic means offered by contemporary technology and contemporary art to visualize data. Ikeda is highlighting here that the vast majority of information out there is not in a format that we can understand and by converting these datasets into sounds and images, he, in a way, rehumanizes the dehumanized data and allows us to interact with it through our senses.

The test pattern series, as its title already suggests, ${ }^{15}$ is a kind of self-reflective examination of the digital video-projecting apparatus, of the sensorial perception, furthermore of the possibilities offered by the media of video installation. Each piece in the series is based on an algorithm programmed by Tomonaga Tokuyama ${ }^{16}$ that converts digital data (texts, sounds, photos or movies) into binary code and visualizes it using black and white barcode-like lines. The alternation of 0 s and $1 \mathrm{~s}$ is visualized as the alternation of these black and white lines. The visual elements tightly accompany the music composed by Ikeda in the same manner (converting data sets into sounds, then arranging them into different rhythm patterns). The alternation

15 "A test pattern is a television test signal, typically broadcast at times when the transmitter is active but no program is being broadcast. Used since the earliest TV broadcasts, test patterns were originally physical cards at which a television camera was pointed, and such cards are still often used for calibration, alignment, and matching of cameras and camcorders. Test patterns used for calibrating or troubleshooting the downstream signal path are these days generated by test signal generators, which do not depend on the correct configuration (and presence) of a camera. Digitally generated cards allow vendors, viewers and television stations to adjust their equipment for optimal functionality. The audio broadcast while test cards are shown is typically a sine wave tone." https://en.wikipedia.org/wiki/Test_card. Last accessed 11. 12. 2019.

He also programmed the algorithm used in the datamatics series. 
of different frequencies, amplitudes and rhythms affects the images, for example deep frequencies correspond to thicker lines and high frequencies give rise to thinner lines, while the speed of the alternation is dictated by the rhythm of the music. [Figs. 7-8.] The velocity of the sound and image is so fast that it sometimes requires the displaying of 400-500 frames/second and the playing back of very high and very low frequencies, thus testing the projecting and the playback devices. Furthermore, the sensorial skills of the visitors are also tested: the perception of rapidly alternating images after a time becomes impossible to the human eye and the audio frequencies may sometimes be too high or too low to be heard by the human ear.

The first edition of the series, titled test pattern [ $\left.n^{0} 1\right]$ (set up at Yamaguchi Center for Arts and Media in Yamaguchi, JP, between March 1 and March 25, 2018) was an audiovisual installation made up of eight LCD monitors and sixteen loudspeakers aligned on the floor in a dark space. The eight rectangular surfaces placed on the floor flicker intensely, the sixteen-channel sound signals are mapped as a grid matrix, passing and slicing the space sharply. Test pattern [nº2] (presented at ARTe SONoro festival in Madrid, ES, between April 22 and June 13, 2010) applied two digital video projectors: one projected the barcode-like images on the wall, the other one on the floor of the dark, cube-shaped room. This variation has already allowed a certain level of immersion, which is further enhanced by the later variations. Test pattern [enhanced version] (set up at New York City, together with the data. tron [advanced version] between May 20 and June 11, 2011) used a 20x15 metre image projected on the floor, while another one used an image projected to a 30x15 metre canvas. In some installations, the image projected on the wall is missing, like in the case of test pattern [ $n^{\circ} 5$ ] (set up at Carriageworks, Sydney, AU, between June 8 and July 1, 2013) or the test pattern [100m version] (set up at Ruhrtriennale, Kraftzentrale, Duisburg, DE, between August 23 and 25, 2013). This implies another kind of immersion: the constant movement of the images projected on the floor in a way forces the visitors to interact by following the velocity of the lines.

The test pattern series test not just the sensorial capacities of the visitors, but also the unconscious attitudes defined by historical experiences in different cultures. Philip Brophy $(2015,222)$ observed that while European and American visitors approached the installations playfully, regarding them as a kind of entertainment, the Japanese audience approached them with fright. Brophy deduces this from the fact that these installations were perceived by the Japanese audience as a representation of floods or tsunamis (natural disasters common in Japan), particularly due to the addition of sine wave tones, which in Japan has been used as a warning signal for natural disasters in television and radio broadcasts. 
The variation titled test pattern [times square] was displayed on the large-sized electric billboards of New York City's Times Square. Between October 1 and 31, 2014, three minutes before midnight, all of Times Square's billboards went dark and the test pattern series' black and white lines appeared on them for three minutes, returning to the usual commercials at midnight. On the one hand, this can be interpreted as a test of Times Square's technical apparatus, but it can also be perceived as a form of social criticism: the testing of a consumer society accustomed to advertising.

Gene Youngblood in his highly influential book Expanded Cinema (1970) describes the Vortex Concerts series created by Jordan Belson and Henry Jacobs as a perfect example of an "immersive projected environment." The experimental concert series was performed at Morrison Planetarium in San Francisco, between 1957 and 1960. In these concerts Belson (who was responsible for the projection) and Jacobs (who selected and composed the music) used the technical apparatus of the planetarium (more than a hundred projectors and loudspeakers, stroboscopes, etc.) to "full fill the hall with images and sounds." Contrary to cinema, which requires a fixed gaze, in the case of Vortex Concerts the images floated all around the spectators, transforming the complete hall into a screen. Youngblood also notes that in the case of the Vortex Concerts the projection became not just a performative act but a carrier of a paradigm of audiovisual experience that also functions as a projection of the collective subconscious (1970, 387-391). Ikeda's audiovisual installations show strong similarities with the Vortex Concert series. On the one hand, the projection in Ikeda's audiovisual installations also have a performative nature, because nothing really happens other than the alternation of abstract images (there is no narrative, no storytelling, etc.) so the focus is on projection and on the medium itself. On the other hand, even though Ikeda's audiovisual installations cannot be described as a projection of the collective unconscious, these works certainly reflect a global phenomenon that has become an unnoticed part of our everyday life (the omnipresence of digital data). Another, and perhaps the most important connection is the loading of spaces with motion pictures, creating immersive environments, in which the medium of sound and the medium of image unify through the human senses as a new sensorial experience offered by the medium of audiovisual installation. ${ }^{17}$

17 An interesting contemporary example of an immersive environment filled with moving images used in a less avant-garde and more commercial manner is the Atelier des Lumières opened in Paris in 2018. A former iron foundry plant was converted into a digital art centre featuring 120 video projectors and 50 loudspeakers, created especially for immersive audiovisual installations (e.g. based on the paintings of Gustav Klimt, Vincent van Gogh, Yves Klein). One of Ikeda's artwork optimized for this space could be an interesting experience. 


\section{The Visitors}

Ikeda bases his works of art mainly on the human perception and the human sensorial functions, making the visitor's role and position an important aspect in his body of work. In the case of Ikeda's audiovisual installations visitors cannot interact directly with the artwork (like in a video game or in an interactive movie), but with their movement through the exhibition space, they can change the point of view, detect new optical effects, and observe different details of the projected images. Moreover, with their bodies, visitors shape the installation itself, since the moving images are often projected onto the bodies of visitors, making them an integral part of the installation. However, this is not a distinctive feature, the same is true for every artwork which applies projected environments. (It is important to note the difference between "projected environment" and "single-channel"/"multichannel" video installations, where the latter can be perceived in a passive way.) In Ikeda's artworks it is the juxtaposition of sound and these projected environments that creates something unique. Not only that image and sound function in perfect synchrony, enhancing each other's synaesthetic effect, but due to the use of high volume, these environments also make it possible to perceive the sound with the whole body, not just with the hearing organs. In this way, these audiovisual installations offer not merely a sensory experience but also a physical one. Ikeda's audiovisual installations can be seen as the opposite of virtual reality, which has at its core the complete disconnection of human senses from nature and matter, even if Ikeda's nature and matter are based on digital data too. The concept of transporting viewers into an enclosed, illusionary visual space is similar, but in the case of VR the presence is virtual, one's body is being in one environment (here) and the subjective experience in another, digital environment (there); in Ikeda's case the presence is real, one's body and one's subjective experience are in the same, digitally altered environment.

Ágnes Pethő suggests a phenomenological approach on filmic intermediality, based on the assumption that "while 'reading' intertextual relations engages our intellectual capacities, 'reading' intermedial relations requires more than anything else, an embodied spectator who gets 'in touch' with the world of the film," and notes, that the "intermediality of film is grounded in the (inter)sensuality of cinema itself, in the experience of the viewer being aroused simultaneously on different levels of consciousness and perception” $(2011,4)$. Based on Vivian Sobchack's notions, Pethő describes the filmic intermediality as a corporeal experience, which uses one's dominant senses of vision and hearing "to speak comprehensibly to 
our other senses." Also based on Sobchack's notions, she uses the metaphor of the "film's body," which she describes as a "complex phenomenon at the 'crossroads' of the specifically cinematic 'game of mirrors' (played between illusion and reality, the projection room and the screen, the 'gaze' and the 'touch')" and which "is perhaps the most comprehensible and 'tactile' aspect of mediality in the cinema that we can think of" (Pethő 2011, 71). Through the example of Abbas Kiarostami's Shirin (2008), Pethô points out that the meeting of one's body and the film's body creates the cinematic experience, which is "clearly located not on the screen but in the 'eyes of the beholder,' on the face and body of the spectator," moreover, "the film's body becomes the spectator's body mirroring the carnal world of the screen, responding to each flicker of the cinematic spectacle” (2011, 77). Applying Pethő's notions onto Ikeda's installations is a valid way to approach the medial relations in these works. On the one hand, Ikeda's abstract images resist reading with one's intellectual capacities; on the other hand, in Ikeda's case we are dealing with a sensorial experience mainly caused by an interaction between the human senses and between media. Entering one of Ikeda's installations, the visitor encounters the body of the audiovisual installation (the abstract digital images, by their nature, unveil their mediality), which becomes the visitor's body. Paul Hegarty, based on Matthew Herbert's notions describes this encounter as experiencing the infinite with "our own nerve endings: in intensely variable streams of visual or [and] sonic information, in what floods the retina" (and floods the eardrum, we may add) (2015, 159). Hegarty also notes that Ikeda makes pieces that "combine visual and audio in installation form, they are precisely not 'audiovisual' in that they are designed to be neither, and the very existence of either sound or image becomes a pleasing sideeffect, a way for limited humans to see into the world of data, much as the scrolling figures of The Matrix (1999) tried to demonstrate" $(2015,159)$.

According to Yvonne Spielmann, “Ikeda's work arguably demonstrates a level of computing in which there is none of that synergetic linkage denoting traditional processes for a conversion or a restructuring of media elements. There is not much point in talking about media elements from different origins. [...] A common level of functioning in programming accompanies computers as simulation machines. On this level, there is no longer any need to undertake transformations altering the structure of different media forms" $(2012,123)$.

Based on these insights, perhaps it can be said that the body of audiovisual installation in the case of Ikeda's works is a body in which the medium of sound and the medium of moving image interact within the visitor's perception. Neither the sound nor the image has a primer nature and due to their simultaneous and 
synchronous presence the medial borders blur within the human perception: the image becomes the visualization of sound and the sound becomes the sonification of the image, both being the dual expression of the same material: data. Moreover, it is presumable that the abstract nature of Ikeda's works (i.e. there is no carnal world on the screens, no representations, no figurative forms, no signs) can initiate cognitive functions too, the visitor unintentionally starts to think about the meaning of these works and perhaps starts to reflect on the functioning mechanisms of his/ her own senses and on the functioning mechanisms of the medium.

\section{Conclusion}

Ryoji Ikeda's audiovisual installations, in addition to creating a dialogue between science and art, by borrowing concepts from the field of physics, information technology, and mathematics, always reflect on the medium of video installation. His digitally created environments are not mimetic representations of the world but rather simulations, which through the inter-sensual stimulation caused by mediums generated from the same raw material of data offer the possibility of getting in touch with something that is naturally untouchable and unreachable. James Bridle in his book New Dark Age: Technology and the End of the Future (2018) argues that the development of technology has exceeded humanity. In the postdigital era we no longer understand the functioning mechanisms of our digital environments. Technology has become the integral part of our everyday life, our digital gadgets have become extensions of our bodies, but the functioning mechanisms are too complex and too abstract to understand. In this sense, Ikeda's body of work perhaps can be seen as a tool which helps us to understand some aspects of our digital environments.

Marshall McLuhan described the analogue film through the example of Charlie Chaplin's Modern Times (1937) as the embodiment of a mechanical era. The film reel and the conveyor, the clockwork and the projector form analogies: they have common medial forms, they organize their material (people standing next to the conveyor, people sitting in the cinema) in a similar way $(1968,317)$. Based on McLuhan's analogy, Ikeda's audiovisual installations perhaps can be described as the embodiments of the data-driven postdigital era: spaces built up from digital data (the Internet for example) inhabited by people who are able to freely roam and form their space. 


\section{References}

Adorno, Theodor W. 1994. The Curves of the Needle. In The Weimar Republic Sourcebook, eds. Anton Kaes, Martin Jay and Edward Dimendberg, 605-607. Berkeley, Los Angeles: University of California Press.

Alexenberg, Mel. 2011. The Future of Art in a Postdigital Age: From Hellenistic to Hebraic Consciousness. Bristol and Chicago: Intellect/University of Chicago Press.

Bridle, James. 2018. New Dark Age: Technology and the End of the Future. New York, London: Verso Books.

Brophy, Philip. 2015. Sine Qua Son: Considering the Sine Wave Tone in Electronic Arts. In Abstract Video: The Moving Image in Contemporary Art, ed. Gabrielle Jennings, 222-236. Oakland: University of California Press.

Cascone, Kim. 2000. The Aesthetics of Failure: "Post-Digital" Tendencies in Contemporary Computer Music. Computer Music Journal vol. 44, no. 4 (Winter): 12-18.

Greenberg, Clement. 1961. Art and Culture: Critical Essays. Boston: Beacon Press. Hegarty, Paul. 2015. Rumour and Radiation: Sound in Video Art. New York,London: Bloomsbury Publishing.

Higgins, Dick. 1984. Horizons, the Poetics and Theory of the Intermedia. Carbondale: Southern Illinois University Press.

Keefer, Cindy. 2015. Visual Music's Influence on Contemporary Abstraction. In Abstract Video: The Moving Image in Contemporary Art, ed. Gabrielle Jennings, 81-98. Oakland: University of California Press.

McLuhan, Marshall. 1968. Die magischen Kanäle [The Magic Channels]. Düsseldorf,Wien: Econ.

Menkman, Rosa. 2011. Network Notebook\#04: The Glitch Moment(um). Amsterdam: Network Notebooks.

Morse, Margaret. 1990. Video Installation Art: The Body, the Image, and the Spacein-Between. In Illuminating Video, eds. Doug Hall and Sally Jo Fifer, 153-167. New York: Aperture.

Moritz, William. 1986. Towards an Aesthetics of Visual Music. ASIFA Canada Bulletin vol. 14, no. 3 (December): 1-3.

Pethő, Ágnes. 2011. Cinema and Intermediality: The Passion for the In-Between. Newcastle upon Tyne: Cambridge Scholars Publishing. 
Sangild, Torben. 2004. Glitch - The Beauty of Malfunction. In Bad Music: The Music We Love to Hate, eds. Christopher Washburne and Maiken Derno, 257-268. New York, London: Routledge.

Spielmann, Yvonne. 2001. Intermedia in Electronic Images. Leonardo vol. 34, no. 1: 55-61.

Spielmann, Yvonne. 2012. Hybrid Culture: Japanese Media Arts in Dialogue with the West. Cambridge: MIT Press.

Youngblood, Gene. 1970. Expanded Cinema. New York: P. Dutton \& Co., Inc.

\section{List of Figures}

Figures 1-4. Stills from the data.tron [WUXGA version] set up in Chiostro del Bramante, Rome, IT, between September 29, 2018 and August 25, 2019. (Stills from a video recorded by the author at Chiostro del Bramante Gallery, Rome, IT, on January 13, 2019.)

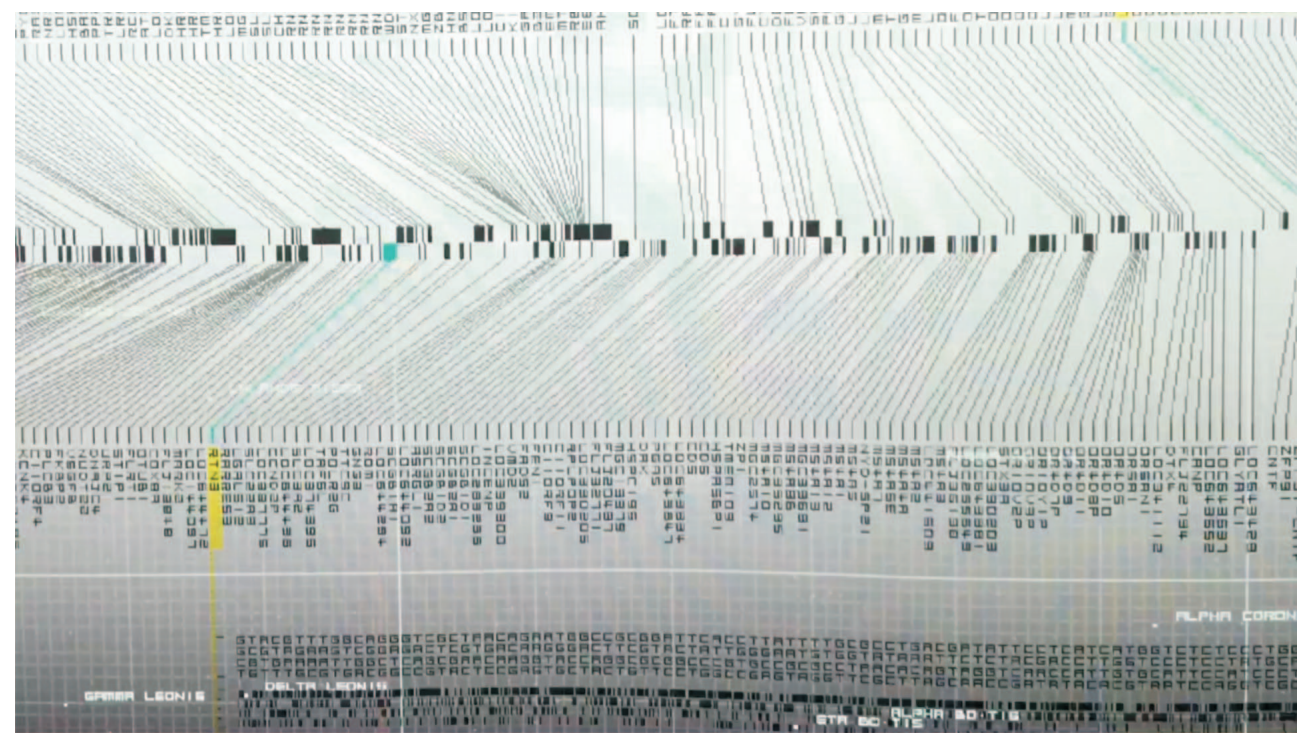



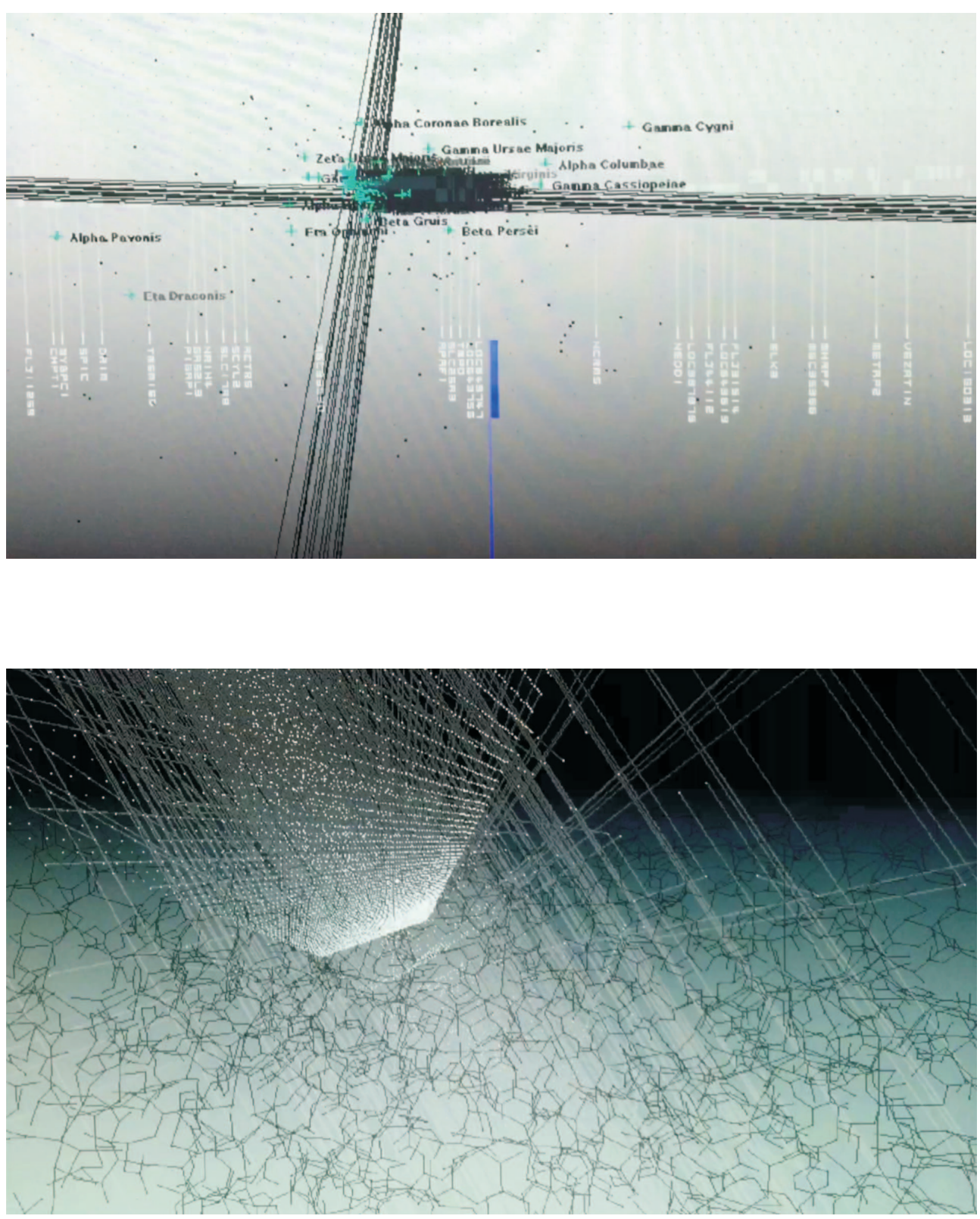


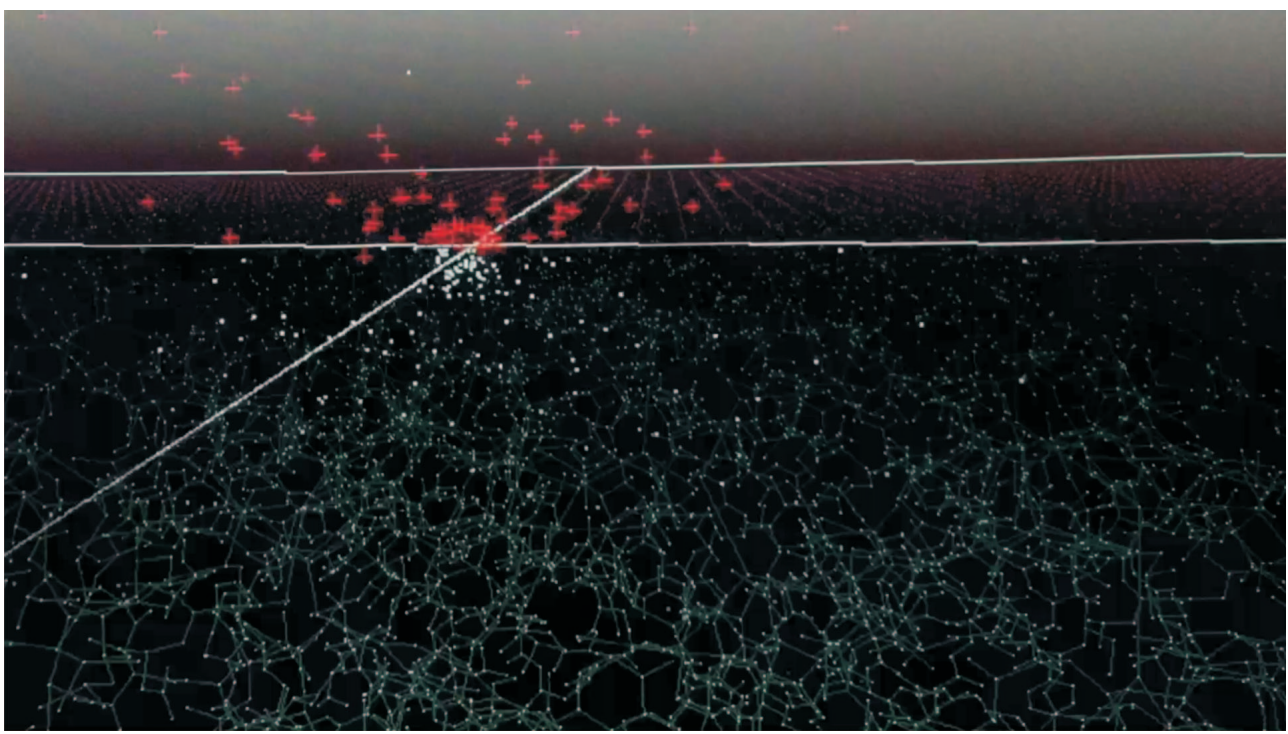

Figures 5-6. spectra[nagoya] near the Nagoya Castle in Nagoya, Japan. (The stills are from a video uploaded to YouTube. https://www.youtube.com/ watch? $v=a n 7 F u W i w d i 0 \& t=6 s$. Last accessed 16. 12. 2019.)

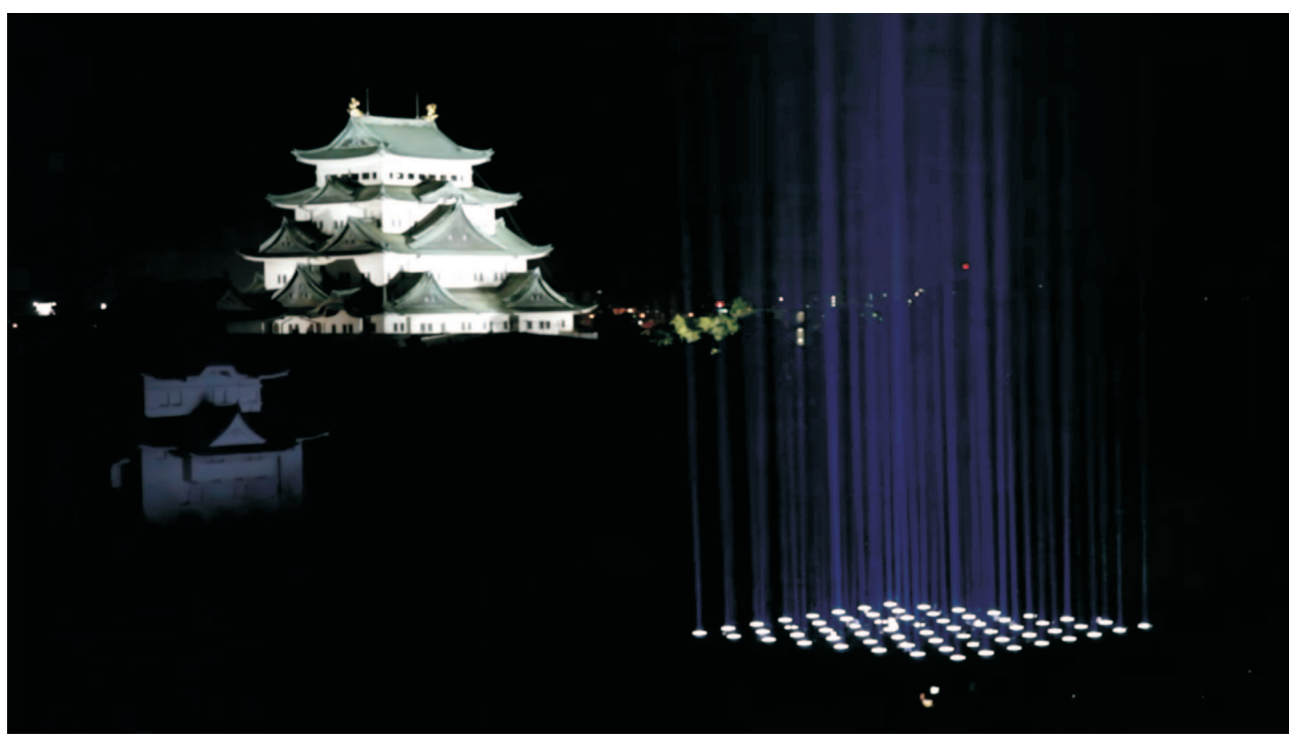




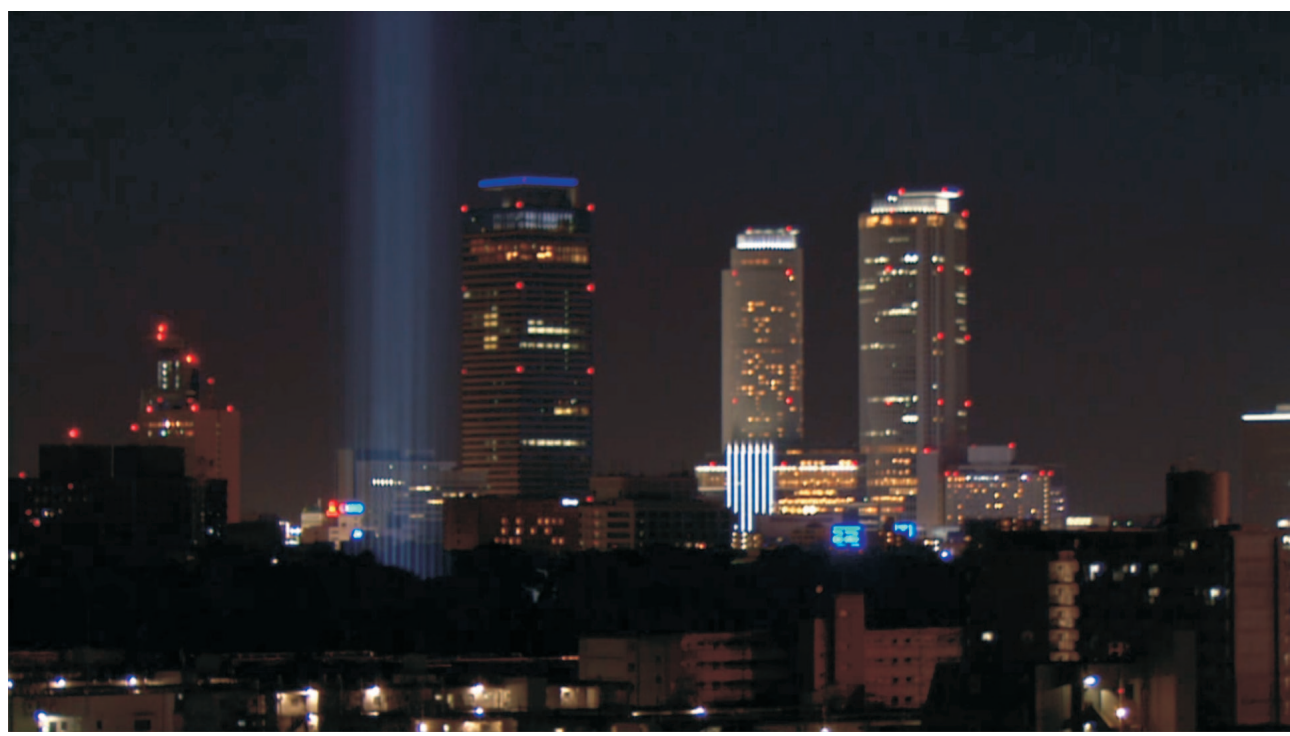

Figures 7-8. Barcode-like images from the test pattern series. (Installation view, photos taken by the author at 180 The Strand Gallery, London, UK, on November 11, 2017.)
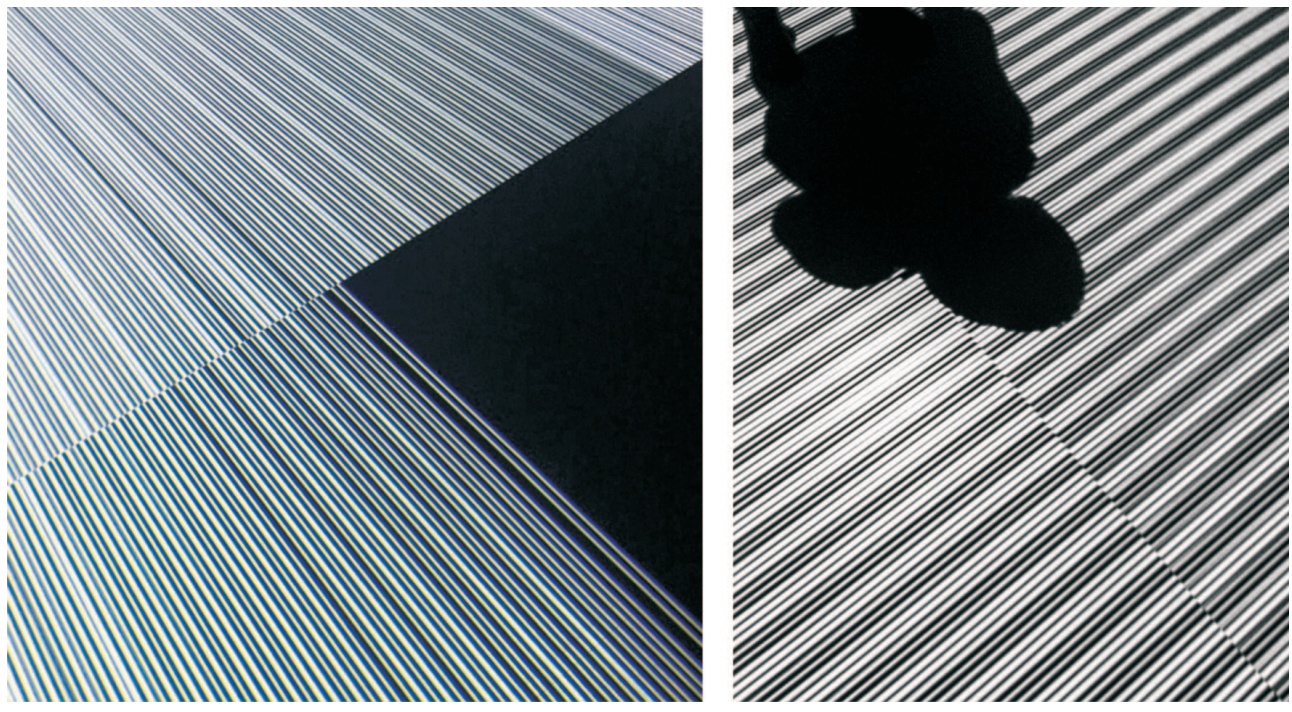